\title{
Enhancing the Teaching of Digital Signal Processing through Project-Based Learning
}

\author{
http://dx.doi.org/10.3991/ijoe.v9i2.2489 \\ Yazan A Alqudah ${ }^{1}$, Esam Qaralleh ${ }^{1}$ and Michelle D Mace ${ }^{2}$ \\ ${ }^{1}$ Princess Sumaya University for Technology, Amman, Jordan \\ ${ }^{2}$ Independent Educational Consultant
}

\begin{abstract}
Engineering education is constantly challenged to bridge the gap between classroom and real world problems. This paper reports on the experience at PSUT to complement the teaching of digital signal processing through project-based learning. A low cost digital stethoscope is utilized by students to record heartbeat sounds and apply DSP concepts to extract vital information from the signal. The ability to apply concepts learned in the classroom to a real world problem was an important element that motivated students. The feedback from students reinforced the effectiveness of these techniques in teaching concepts of digital signal processing.
\end{abstract}

Index Terms-Project based learning; DSP; heart rate analysis.

\section{INTRODUCTION}

Engineering education is in a constant state of evolution. While teaching has primarily been traditional in nature in the past, with a lecture/exam format, current education learning methods suggests that this alone may be an ineffective method to maximize student learning and to prepare for real world application.

Engineering courses should achieve certain objectives to be met through the curricula; the students should learn to face real world problems with different complexities by developing the skills needed for learning and group work [1]. Recently, accreditations institutions like ABET [2],[3], and curricula design associations, such as IEEE/Association for Computing Machinery (ACM) and Computer Curricula 2001 [4] have suggested specific achievable objectives be implemented in the curricula.

ABET's criteria for accrediting engineering programs for 2012-2013 requires that engineering courses be designed to meet a vast array of desired outcomes [2]. Criteria 3, Student Outcomes, were designed as a guide for the skills students should achieve through their engineering coursework by the time of graduation. ABET's Engineering Accreditation objectives states that engineering courses should encourage students to apply their technical knowledge, conduct experiments, have an understanding of contemporary engineering issues, and be able to analyze and interpret data Students should also be able to utilize modern engineering tools that are needed for engineering practice [2]. Unfortunately, there had been a disparity between the formulated educational standards and those actually achieved by recent engineering graduates.

According to research by Mills and Treagust [5], engineering students are graduating with a good fundamental knowledge of engineering science concepts, but they don't know how to apply this information to the real world. This poses problems for future engineers being unprepared for their careers upon graduation. Accreditation and curricula design associations suggest that engineering courses be crafted to stimulate students to think and to apply their knowledge to solve real world's problems and participate in projects much like those they would find in their careers. The traditional educational context, which is based on "chalk-and-talk" to transfer knowledge from a teacher to a class of students, makes this suggestion difficult to achieve.

To meet the above advised transition in teaching engineering courses to a more hands-on approach, two learning theories are recommended: Problem-Based Learning and Project-Based Learning (PBL).

Problem-based learning is not a new approach to learning. It was first pioneered in 1968 at McMaster University, a Canadian medical school, in response to the inability of students to apply the scientific knowledge they gained in the classroom to the clinical setting. An "active, student-centered approach" to learning, problem-based learning encourages students to be an active part of the learning process by conducting research, applying theory, and employing knowledge and skills to a preset problem or question [6]. Problem-based learning is nearly always a "student learned approach" meaning that the students learn, not through a traditional lecture by their professor but through research conducted on their own. Although the roots of problem-based learning are in medicine, it has been adopted as pedagogy in engineering and other scientific fields.

The second hands-on learning approach that has evolved in the classroom is Project-Based Learning (PBL). This approach introduces the theory that the best learning comes from actually participating in the learning process through a project or experience. Project Based Learning is said to have a long history, starting in the times of Confucius and Aristotle [7]. Both philosophers were proponents of "learning by doing." In the 20th century, John Dewey, an American educational theorist and philosopher also echoed these sentiments arguing that projects and life experiences prepare students for learning in the real world. He said "Education is not preparation for life; education is life itself." Early-childhood educational expert Maria Montessori and developmental psychologist Jean Piaget, have also encouraged various forms of project-based learning in education [7].

More recently, in the late 1990s, the Buck Institute for Education (BIE) [8] has started promoting the concept of 
PBL in the classroom. BIE is now the official advocate for PBL in the US.

According to BIE [8], "In Project Based Learning $(P B L)$, students go through an extended process of inquiry in response to a complex question, problem, or challenge. While allowing for some degree of student "voice and choice," rigorous projects are carefully planned, managed, and assessed to help students learn key academic content, practice 21st Century Skills (such as collaboration, communication \& critical thinking), and create highquality, authentic products \& presentations." Simply stated, Project-Based Learning is a technique that encourages learners to participate in a real-life application, by merging the course content with a relevant project.

Project-Based Learning can be an individual or group activity that is worked on for a specified period of time (for example, one semester), resulting in a product, presentation, or report. It typically has a set timeline and milestones, much like projects engineers will work on upon graduation.

Although both approaches have similarities that sometimes cause "gray lines" between them, the major differentiator is the end result of the learning experience. The main distinction is that problem-based learning emphasizes acquiring knowledge through the preset problem or question, while project-based learning emphasizes applying and integrating knowledge to enhance the learning experience [9]. Research also suggests that project-based learning tasks mirror the professional environment more than problem-based tasks, allowing for a greater learning experience for students [10]. Project-based strategies also tend to complement specific content learned in courses (while this is not a requirement of the problem-based approach) [9]. For these reasons, this research will focus on a project-based approach to learning digital signal processing (DSP).

Project-based learning, as with any learning system, has its own set of advantages and challenges. One of the many advantages of this approach is that students are motivated by the learning experience since they are an active participant of the work, rather than being "handed" the information and the solution by the professor [5]. Project-based learning also allows students to learn to solve problems through a professional, real world application which adds more excitement to the course experience. Project-based learning has also been shown to improve teamwork and communication skills and allow students to improve their organizational and management skills. The latter are all valuable skills for future engineers.

Project-based learning also poses some challenges in the classroom setting [7]. For instructors, the use of project-based learning requires extensive planning and management skills. Instructors may also be forced to take on a more facilitative role in the classroom, which requires more time and effort on their part. It has also been shown that the project-based approach is not always able to cover the wide range of topics that are covered in the course [11]. For students, project-based learning requires extra effort and initiative and may poses difficulties to students given their other course work [18]. Students need to develop time management skills, organizational skills, and sometimes rely on other peers for group projects [12]. According to research completed at Monash University in Australia [5], the students' main issue with project-based learning were the extent of time for project work, and problems with team members that did not fulfill their fair share in project work. Their research indicated that learning more about teamwork and problem-solving skills were essential components that needed more attention in follow-up project-based learning courses.

Project-based learning is becoming increasingly popular in engineering [3-7]. Projects can operate in widely diverse contexts and approaches. They may be used by a single lecturer to guide the students to apply theoretical knowledge to targeted problems. PBL aims to enhance engineering education by improving student's skills and grasp of target knowledge. The main objective of any engineering department is to motivate and inspire students to learn engineering both in theory and in its practical aspects outside the classroom.

PBL components should be well-designed to complement theoretical course contents. This project was purposely planned to offer flexibility for the students. Students have the freedom to conduct the experiments in nearly any location due to its portability. The environment is intended to improve the students' understanding of how filters/samplers affect the input signal. Working on familiar signals (e.g. heart beating sound) will allow the students to grasp more fundamental concepts in DSP.

This work is organized as follows: In Section II we introduce project based learning, Section III briefly describes the course content, and Section IV introduces project-based learning implementation, Section $\mathrm{V}$ the implementation of the project. Section VI describes learning modules associated with the project and Section VII reports on student feedback. Finally, the conclusion is provided in Section VIII.

\section{PROJECT-BASED LEARNING IN APPLIED ENGINEERING COURSES}

In literature, researchers apply the concept of projectbased learning on different courses and measure the success of students compared with the traditional lectureonly format. In [12], the authors developed five different case studies by different teams of students. Each team is encouraged to be involved in their peer's team case study. This project promoted collaboration and other skills that are needed for future engineers in the work environment. This multiple case study project offered students a broad and yet deep learning of curriculum content while being involved in a real-world project. The research improved students' skills in sharing workloads, offered students opportunities to read and write technical documentation, and improved their self-organizing skills.

Programmable logic design and computer architecture are discussed in [13]. The students were asked to design their own Instruction Set Architecture and to implement their design on FPGA. They applied the fundamentals for computer architectures using hardware description language HDL.

While in [14] the teaching of 2 elective undergraduate courses in the topics of power supplies and photovoltaic electricity were presented using PBL methodology. The students who participated through five years achieved positive results, encouraging other student's enrollment in these elective courses. Surveys with participating students indicated that they were satisfied with the courses and 
their experience in participating in a project within the coursework.

Projects driven learning has proved to be successful in various courses in different disciplines. Power system engineering discussed in [15]. The PBL proposed was based on modeling and analyzing a power system. A power system laboratory was established for this purpose to give students the opportunity to work on an actual case study. The students' feedback confirmed the effectiveness of PBL in such a specialized course with advanced contents. Both theory and laboratory were included and survey feedback indicates that both technical content and professional skills were achieved in this research. This research has suggested that a "hybrid" form of PBL, that utilizes learning through projects and delivery course content through lectures be utilized for optimized student learning.

Electronics System curricula incorporated PBL for making electronics more appealing for students as proposed in [10]. The author's claim that electronics is the foundation for many disciplines motivated the design and implementation of this curriculum. The curriculum structure supports multidisciplinary projects using the projectbased learning strategy. The curriculum structure included eight courses: four theoretical and four PBL. A common hardware platform was used to enable multidisciplinary projects to assist the above claim. The evaluation of the proposed curricula, completed after four years, has reported significant advances in student's knowledge and skills to develop more sophisticated and realistic electronic systems.

Digital signal processing courses are rich with mathematical concepts, system analysis, and synthesis. Also, DSP addresses real world practical engineering applications. Student's difficulty to understand this course is due to the gap between the mathematical formulae and practical applications to engineering problems. Authors in [16] presented a DSP project utilizing special DSP architecture that enables students to accomplish critical stages of the project such as architecture choice and application of the design technique by allowing studying the other students' work.

The work in [17] is one of the first that provides an indepth look at project-based learning in the area of DSP. The research was based on a multiple-year study, in an undergraduate course. The research indicated that students preferred the hands-on learning offered in the course, despite that fact that it was more time-intensive. Students agreed that the projects enhanced their understanding of DSP concepts.

On the other hand, research by [18] looks at the design of project-based assignments that incorporates both theoretical and applied elements of DSP concepts to a diverse student community. The open-ended feedback obtained from students indicates that the assignments enhanced the students' understanding of DSP concepts when the students put the concepts to practice. The study leads to the conclusion that presenting hands-on applications is most effective to students after basic DSP concepts have been taught.

Engineering education is constantly challenged to balance fundamental knowledge and student centered learning. Driven by industry input and accreditation bodies, project-based learning is proposed as a strategy to address relating theoretical topics to industrial practices, provide design experience, and improve communications skills and team work.

\section{DigITAL SigNAL PROCESSING AT PSUT}

The Digital Signal Processing (DSP) course is offered in the $4^{\text {th }}$ year of a 5-year undergraduate curriculum. The course is offered as 3 credits and covers typical topics covered by an undergraduate DSP course including discrete-time signals and systems, sampling and reconstruction of signals, Z-transform, Infinite Impulse and Finite Impulse response filters (IIR and FIR), and Discrete Fourier Transform (DFT).

The course is expected to achieve several ABET outcomes including [2]:

- Ability to apply knowledge of mathematics, science, and engineering

- Ability to design a system, component, or process to meet desired needs

- Ability to identify, formulate and solve engineering problems

- Ability to use the techniques, skills, and modern engineering tools necessary for engineering practice.

The current curriculum does not contain a laboratory work that complements class lectures. Any practical applications of the theories studied have to be provided through assignments and projects.

\section{PROJECT-BASED LEARNING IMPLEMENTATION}

The objective is to design a low-cost project that best facilitates student learning. The project proposed for this course is to apply basic DSP techniques to improve recorded heart beat sounds. The hardware part of this project is simple to construct. It uses a digital stethoscope (i.e. a medical stethoscope attached to a microphone) connected to the audio jack of the PC. Once the heartbeats are recorded, students can apply different DSP techniques learned in the class using MATLAB. The low cost of the project made it easy for all students to run the project.

PBL components should be well designed to complement theoretical course contents. In this work, a project is proposed with two parts: the hardware part represented by a digital stethoscope connected to the audio jack of the $\mathrm{PC}$; and the software part represented by running DSP modules (e.g. $1^{\text {st }}$ or $2^{\text {nd }}$ order filter, up/down samplers) in a MATLAB environment. The flexibility gives students freedom to conduct the experiment in nearly any location. The programming environment was designed to improve the students' understanding of how filters/samplers affect the input signal. Working on familiar signals (e.g. heart beating sound) will allow the students to grasp more fundamental concepts in DSP.

In designing a project that reinforces the theory studied in the classroom, it was decided that the project should meet the following objectives:

- The project should have a practical application that ties theory to real world problems that engineers might face.

- The project should accommodate major topics studied in class room. 
- The project should provide flexibility to students (i.e. they should be able to work on task according to their schedule).

To meet the above requirements, we utilized vital signs, in particular a heartbeat audio recording, as a sample file that students study and apply different analysis and design techniques. The heart sounds is a result of blood flow of the beating heart. In healthy adults, there are two sounds generated by the movement of the heart. The first sound (S1) is a result of ventricular contraction, or systole, causing block of reverse blood flow due to closure of atrioventricular valves. The second sound (S2) is produced by the relaxation of ventricles at the beginning of ventricular diastole shutting valves between the ventricles and arterial vessels.

The objective of the project is to determine timing of S1 and S2 utilizing the recorded signal. To personalize the experience and make it more exciting, students are given the choice to record their own heartbeat sounds to analyze. For students who chose not to record their own audio, several sample audio files are made available for download on the course website.

\section{IMPLEMENTATION}

The hardware used is rather simple. It consists of a stethoscope that is coupled with an audio microphone to enable the recording through a $\mathrm{PC}$ or a mobile phone. The hardware is illustrated in Fig. 1.

The analysis component is provided by Matlab software. Matlab enables students to record the audio file and save it to a disk. The command in Matlab enables recording using different sampling rate. A typical audio signal will look similar to the one displayed in Fig. 2. Once the audio signal has been obtained, student can start processing the data. The next section will look at the different learning modules that are proposed.

\section{LEARNING MODULES}

The project runs throughout the semester. In the first week of the course, students are asked to record their heart sound or adopt one from available recordings. The tasks and assignments are added on a weekly basis based on the theoretical concepts studied in classroom.

In this section, we describe different modules in the project and their learning objectives.

\section{A. Sampling Theory}

The first module aims at familiarizing students with sampling theorem and digital signal representation. The students are expected to display the sampled data using correct time reference. Thus students utilize sampling time to generate a vector that represents sampling times. Students are requested to change the sampling time of the audio signal using a Matlab command and comment on the impact on the audio signal, as well as determine the lowest sampling rate that meets Nyquist sampling theorem.

\section{B. Filter Design}

Several techniques exist for designing digital filters. This module requires students to apply different techniques to their audio signal with the objective of reducing noise. For each filter, the calculation of filter order and specifications are performed prior to filter implementation. The filter is then applied to the sample file and input and output are compared.

During this module, students are expected to implement FIR and IIR filters. For each filter the students are expected to propose their own cut-off frequencies and filter gain based on their sample signal. During the course of the project, students are expected to design two IIR filters and one FIR filter. The IIR filters are specified to be Butterworth and Chebyshev filters. After students determine filter specs, they utilize Matlab to implement the filter and obtain filter frequency response and output. A typical filter will look similar to Fig. 3. The output of the filter is then applied to averaging filter to obtain a graph that highlights S1 and S2 as shown in Fig. 4.

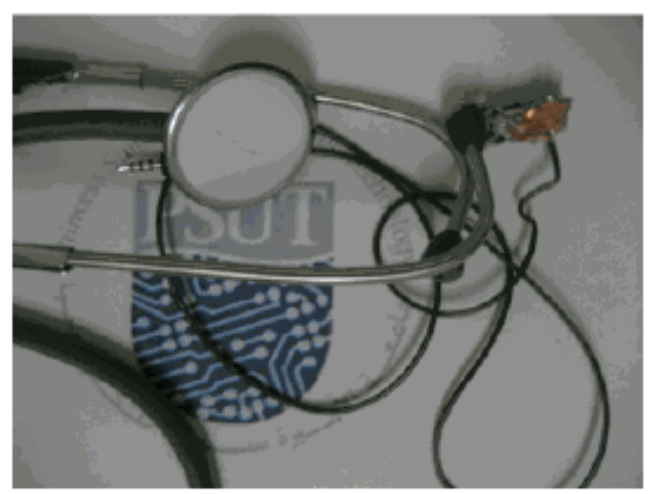

Figure 1. An assembled stethoscope with microphone to convert audio to an electrical signal.

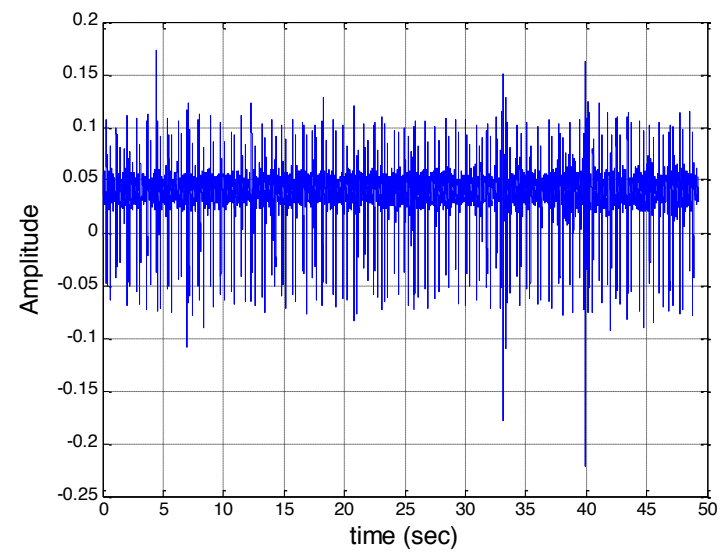

Figure 2. Raw audio recording of heart sound
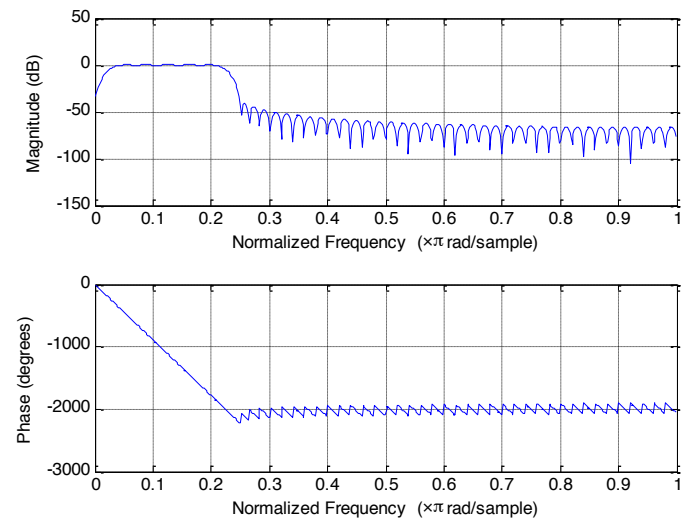

Figure 3. Bandpass FIR filter 


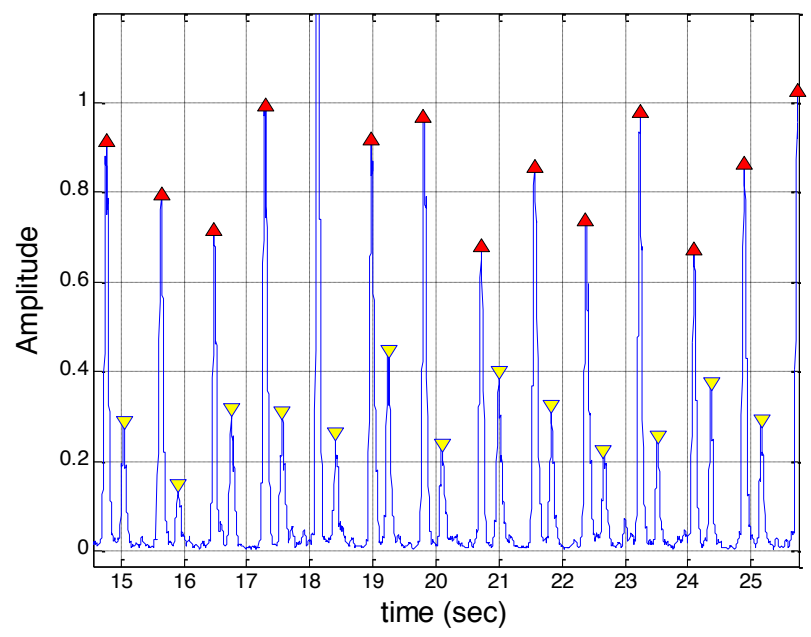

Figure 4. Averaging Fitler Output

\section{Frequency Analysis}

To fully understand the impact of signal processing on the sampled signals, students are asked to calculate and display frequency analysis of filter inputs and outputs.

The students utilize FFT and IFFT command in Matlab to calculate the discrete frequency transform. For each filter, the students are asked to plot and comment on the DFT of input and output signals.

\section{STUDENT FEEDBACK}

The project-based learning utilizing vital signs has been adopted for two semesters. The students are asked to complete a survey that assesses the effectiveness of the project in reinforcing DSP concepts.

Table I summarizes the feedback from students after completing the project. For each question, students are asked to rate their assessment by entering a numerical value to indicate (1) for strongly agree and (5) for strongly disagree.

As the table shows, the majority of students found the project to be an effective tool in helping them to apply concepts learned in the course to solve a real engineering problem. The majority also show more interest in DSP as a result of the project. The fact that the project has a practical, "real life" aspect motivated the students and made the work more interesting. Overall, nearly all the students agreed that the time and effort spent on the project were worth it.

TABLE I

STUDENT INPUT

\begin{tabular}{|l|c|c|c|c|c|}
\hline \multicolumn{1}{|c|}{ Table Head } & \multicolumn{6}{|c|}{ (1)Strongly disagree (5)Strongly agree } \\
\hline & $\mathbf{( 1 )}$ & $\mathbf{( 2 )}$ & $\mathbf{( 3 )}$ & $\mathbf{( 4 )}$ & $\mathbf{( 5 )}$ \\
\hline $\begin{array}{l}\text { The project reinforced } \\
\text { concepts in class }\end{array}$ & $\mathbf{0}$ & $\mathbf{1}$ & $\mathbf{8}$ & $\mathbf{2 0}$ & $\mathbf{6}$ \\
\hline $\begin{array}{l}\text { The project raised my interest } \\
\text { in DSP }\end{array}$ & $\mathbf{1}$ & $\mathbf{1}$ & $\mathbf{1 0}$ & $\mathbf{1 7}$ & $\mathbf{6}$ \\
\hline $\begin{array}{l}\text { Having real engineering } \\
\text { problem made the project } \\
\text { more interesting }\end{array}$ & $\mathbf{0}$ & $\mathbf{2}$ & $\mathbf{1 2}$ & $\mathbf{1 1}$ & $\mathbf{1 0}$ \\
\hline $\begin{array}{l}\text { The project is worth the time } \\
\text { and effort }\end{array}$ & $\mathbf{0}$ & $\mathbf{1}$ & $\mathbf{9}$ & $\mathbf{1 5}$ & $\mathbf{1 0}$ \\
\hline
\end{tabular}

\section{CONCLUSION}

This work reported on the experience of adopting project- based learning to complement coursework in a DSP course. By adopting a practical problem, students were excited about applying the concept to solve the problem. The feedback from students reinforced the effectiveness of the tool in teaching fundamental concepts of DSP to the students.

\section{REFERENCES}

[1] D.Ausubel, J.Novak, and H. Hanesian, Educational Psychology: A Cognitive View, $2^{\text {nd }}$ ed. NewYork: Holt, Rinehart, and Winston, 1978.

[2] ABET, Criteria for Accrediting Engineering Programs. Engineering Accreditation Commission of the Accrediation Board of Engineering and Technology, Baltimore, MD (2012). [ONLINE]. Available: http://www.abet.org/DisplayTemplates/DocsHandbook. aspx?id=3143

[3] R. Felder, R. Brent, "Designing and teaching courses to satisfy the ABET Engineering Curricula," Journal of Engineering Education, vol.91, no.1, pp.7-25, Jan. 2003. http://dx.doi.org/10.1002/j.21689830.2003.tb00734.x

[4] ACM/IEEE Computer Society Computing Curricula (2004). [Online]. Available: http://www.computer.org/education/cc2001

[5] J.E. Mills and D. F. Treagust. "Engineering education-Is problem-based or project-based learning the answer?" Australasian Journal of Engineering Education 3 pp. 2-16, 2003.

[6] J. Savery, "Overview of problem-based learning: Definitions and distinctions." Interdisciplinary Journal of Problem-based Learning 1.1 (2006): 3.

[7] S. Boss, Project-Based Learning, A Short History. The George Lucas Education Foundation. [ONLINE]. Available: http://www.edutopia.org/project-based-learning-history

[8] Buck Institute for Education. [ONLINE]. Available: http://www.bie.org/about/the_bie_story/).

[9] J.C. Perrenet, P. A. J. Bouhuijs, et al. "The suitability of problembased learning for engineering education: theory and practice." Teaching in Higher Education vol. 5 no. 3, pp. 345-358, 2000. http://dx.doi.org/10.1080/713699144

[10] J. Macías-Guarasa et al. "A project-based learning approach to design electronic systems curricula." Education, IEEE Transactions on vol. 49, no. 3, pp. 389-397, Aug. 2006. http://dx.doi.org/10.1109/TE.2006.879784

[11] B. G. Ladewski, J. S. Krajcik, et al. "A middle grade science teacher's emerging understanding of project-based instruction."The Elementary School Journal, pp. 499-515, 1994. http://dx.doi.org/10.1086/461780

[12] A. Martínez-Monés et al. "Multiple case studies to enhance project-based learning in a computer architecture course." Education, IEEE Transactions on vol. 48, no. 3, pp. 482489, Aug. 2005. http://dx.doi.org/10.1109/TE.2005.849754

[13] C.M. Kellett, "A Project-Based Learning Approach to Programmable Logic Design and Computer Architecture." Education, IEEE Transactions on vol. 55, no. 3, pp. 378-383, Aug. 2012. http://dx.doi.org/10.1109/TE.2011.2179301

[14] F. Martinez, L. C. Herrero, et al. "Project-based learning and rubrics in the teaching of power supplies and photovoltaic electricity." Education, IEEE Transactions on vol. 54, no. 1 pp. 87-96, Feb. 2011. http://dx.doi.org/10.1109/TE.2010.2044506

[15] N. Hosseinzadeh, M.R. Hesamzadeh. "Application of ProjectBased Learning (PBL) to the Teaching of Electrical Power Systems Engineering." Education, IEEE Transactions on vol. 55, no.4, Nov. 2012.

[16] I. Milentijevic and V. Ciric. "Project-based learning environment for special purpose DSP architectures" $9^{\text {th }}$ International Symposium on Signal Processing and Its Applications, ISSP, Sharjah, United Arab Emirates, 2007.

[17] A. Eliathamby, and J. Epps. "Project-based learning in digital signal processing: Development and experiences." Digital Signal Processing Workshop and IEEE Signal Processing Education Workshop (DSP/SPE), IEEE. 2011. 
Enhancing the Teaching of Digital Signal Processing through Project-Based Learning

[18] Nelson, Jill K. "Using project-based assignments in a graduatelevel digital signal processing course." In Proc. Fourth IEEE Signal Proc. Educ. Workshop, pp. 135-140. 2006.

\section{AUTHORS}

Yazan A Alqudah and Esam Qaralleh are with Princess Sumaya University for Technology, Amman, Jordan.

Michelle D Maci is Independent Educational Consultant.

This article is an extended and modified version of a paper presented at the the Interactive Mobile and Computer Aided Learning (IMCL2012), held in November 2012, at Princess Sumaya University for Technology, Amman, Jordan. Received 24 January 2013. Published as resubmitted by the authors 25 April 2013. 